\title{
The effect of carbon nanotubes on the mechanical and damping properties of macro-defect-free cements
}

https://doi.org/10.1515/secm-2020-0005

Received Dec 02, 2019; accepted Jan 21, 2020

Abstract: The effect of CNTs on the mechanical and damping properties of macro-defect-free (MDF) cements was studied, and polyvinyl alcohol (PVA) fibers were also studied as a contrast. It was found that the compressive strength of MDF cements was not significantly affected by the two types of fibers. The CNTs enhanced the flexural strength of MDF, while PVA fibers made negative contribution. The strengthening mechanism of flexural strength of MDF cements by CNTs can be summarized as fiber bridging, crack deflection and fiber slippage. For the damping properties, the proper contents of CNTs and PVA fibers improved the loss factor significantly. The interface transition zone (ITZ) between the PVA fibers and matrix was large, which was favorable for fiber slippage. The damping property of MDF cements with CNTs was mainly due to the slippage between the inner tubes of the CNTs rather than the slippage between the CNTs and matrix.

Keywords: Macro-defect-free cements; Carbon nanotubes; Mechanical property; Damping property

\section{Introduction}

Macro-defect free (MDF) cements are ultra-high performance cement-based materials developed by Birchall [1] in the early 1980s. The flexural strength of MDF cements can reach up to $300 \mathrm{MPa}$. MDF cements are composite materials obtained by mixing, high shear and hot pressing. Because of the high-speed shear and mixing in the manu-

\footnotetext{
${ }^{\star}$ Corresponding Author: Zhang Wenhua: Department of Civil Engineering, Nanjing Forestry University, Nanjing, China, 210037; Email: zhangwenhua2009@163.com Wu Peipei, Zeng Weizhao, Yang Fenghao: Department of Civil Engineering, Nanjing Forestry University, Nanjing, China, 210037 Zhang Yunsheng: Department of Materials Science and Engineering, Southeast University, Jiangsu Key Laboratory of Construction Materials, Nanjing, China, 211189
}

facturing process, MDF cements avoid the large pores and defects caused by the residual air and insufficient mixing, which makes MDF cements have unique properties [2]. Calcium aluminate cement (CAC) and polyvinyl alcohol (PVA) are the most widely utilized materials for the production of MDF cements, and the flexural strength can generally reach 150-300 MPa. Ordinary Portland cement and polyacrylamide can also be used for the production of MDF cements, and the flexural strength is only $60-120 \mathrm{MPa}$ [3].

Since the appearance of MDF, many scholars have studied MDF cements. It was found that the significant increases in flexural strength achieved in MDF cements were attributed to a reduction in the density of defects in the materials as well as to chemical reactions occurring between the organic constituent and inorganic ions coming from the hydration products of the cement. The high shear stress produced by the open mill can break the $\mathrm{C}-\mathrm{C}$ bond in the polymer chain into two active macromolecular functional groups with equal molecular weight. The macromolecular functional groups can be cross linked with CAC hydration products to form metal carboxylate [47]. The addition of silica fume can effectively improve the strength of ordinary cement-based materials, but it had an adverse effect on MDF cements. It was suggest that silica fume did not react with calcium hydroxide and worked as an inert filler in MDF cements [8]. In addition, it was found that the addition of fiber could improve the flexural strength and fracture toughness of MDF cements. The fibers formed a network structure in the MDF cements that limited the volume change of the material and improved the mechanical properties. And the surface-modified fiber could strengthen the bonding with the matrix to further enhance the bending strength [9].

With the rapid development of nanotechnology, nanometer materials have been widely used in various industries, and it is the most dynamic research direction in the field of new materials research. Nanotechnology involves a wide range of subject areas, including physics, chemistry, biology, medicine, materials science, information science, energy science, etc. It is a highly interdisciplinary and comprehensive discipline [10]. At present,

๑ Open Access. () 2020 Z. Wenhua et al., published by De Gruyter. (CC) BY 4.0 License 
Table 1: Chemical composition of the cement.

\begin{tabular}{ccccccccccccc}
\hline Component & $\mathrm{SiO}_{2}$ & $\mathrm{Al}_{2} \mathrm{O}_{3}$ & $\mathrm{Fe}_{2} \mathrm{O}_{3}$ & $\mathrm{CaO}$ & $\mathrm{K}_{2} \mathrm{O}$ & $\mathrm{TiO}_{2}$ & $\mathrm{MgO}$ & $\mathrm{Na}_{2} \mathrm{O}$ & $\mathrm{SO}_{3}$ & $\mathrm{P}_{2} \mathrm{O}_{5}$ & $\mathrm{Cl}$ & $\mathrm{NiO}$ \\
\hline $\begin{array}{c}\text { Content } \\
\text { (mass\%) }\end{array}$ & 53.968 & 31.148 & 4.16 & 4.012 & 2.035 & 1.133 & 1.011 & 0.888 & 0.727 & 0.673 & 0.134 & 0.109 \\
\hline
\end{tabular}

many researchers have added nanometer materials to ordinary concrete and ultra-high performance concrete. The conclusions showed that the mechanical properties and damping properties were improved [11-15]. The Koratkar team [16] combined the CNTs with the polymer and found that the loss modulus was increased by more than 10 times while maintaining the stiffness of the composite. MDF cements are similar to polymers because their internal structures are uniform and dense. But up to now, there is no research on adding nanometer materials to MDF cements. Moreover, the internal structure of MDF cements is dense, the porosity is low, and the pore size is small. Therefore, the influence of nanometer materials on the mechanical and damping properties of MDF cements may be completely different from that of ordinary cementbased materials. The addition of nanometer materials can even play many unknown functions.

Since CNTs were discovered in 1991, they have become ideal reinforcements for various matrix materials due to their excellent mechanical properties, chemical stability and electrical conductivity [17]. Therefore, CNTs were added to MDF cements to study the effects of nanometer materials on the mechanical and damping properties of MDF cements in this study. In order to compare the different effects of nanometer fibers and micrometer fibers on MDF cement, PVA fibers were added as a contrast. The addition of fibers of different scales can make a more comprehensive understanding of the influence of fibers on the mechanical and damping properties of MDF cements.

In the experiment, MDF cements with three different content of CNT (0.05, 0.1, 0.15 wt.\%) and two different content of PVA fiber $(0.5,1$ vol.\%) were prepared by a twin roller mill. The compressive strength and flexural strength of the specimens were measured, and the damping property of the specimens at different frequencies was measured by dynamic thermomechanical analyzer. At last, the microstructure and interface transition zone (ITZ) between the two fibers and the matrix were observed by Thermal Field Emission Scanning Electron Microscope (TFE-SEM), and the influence mechanism of the two fibers on mechanical properties and damping property was analyzed.
Table 2: Properties of the MWCNT used in this study.

\begin{tabular}{cccc}
\hline $\begin{array}{c}\text { Outer } \\
\text { diameter }\end{array}$ & Length & Purity & Specific surface area \\
\hline $50 \mathrm{~nm}$ & $>10 \mu \mathrm{m}$ & $>95 \%$ & $40-300 \mathrm{~m}^{2} / \mathrm{g}$ \\
\hline
\end{tabular}

Table 3: Properties of PVA fiber.

\begin{tabular}{lcccc}
\hline $\begin{array}{c}\text { Norminal } \\
\text { strength }\end{array}$ & $\begin{array}{c}\text { Fiber } \\
\text { diameter }\end{array}$ & $\begin{array}{c}\text { Fiber } \\
\text { length }\end{array}$ & $\begin{array}{c}\text { Young's } \\
\text { modulus }\end{array}$ & $\begin{array}{c}\text { Fiber } \\
\text { elongation }\end{array}$ \\
\hline $1600 \mathrm{MPa}$ & $40 \mu \mathrm{m}$ & $12 \mathrm{~mm}$ & $40 \mathrm{GPa}$ & $6 \%$ \\
\hline
\end{tabular}

Table 4: Mix proportions of the test specimens(g).

\begin{tabular}{cccccc}
\hline $\begin{array}{c}\text { Test } \\
\text { Specimen }\end{array}$ & cement & Water & PAM & $\begin{array}{c}\text { CNT water } \\
\text { dispersion }\end{array}$ & $\begin{array}{c}\text { PVA } \\
\text { fiber }\end{array}$ \\
\hline Control & 400 & 60 & 32 & 0 & 0 \\
C1 & 400 & 58.2 & 32 & 2 & 0 \\
C2 & 400 & 56.4 & 32 & 4 & 0 \\
C3 & 400 & 54.6 & 32 & 6 & 0 \\
P1 & 400 & 60 & 32 & 0 & 0.84 \\
P2 & 400 & 60 & 32 & 0 & 1.69 \\
\hline
\end{tabular}

\section{Experimental program}

\subsection{Raw materials}

The cement used in this experiment was White Portland Cement type 52. 5, purchased from Jiangxi Yin Shan White Cement Co., Ltd. The chemical composition of the cement is listed in Table 1. The Specific surface area of the cement is $3800 \mathrm{~cm}^{2} / \mathrm{g}$ and the specific gravity is $3.11 \mathrm{~g} / \mathrm{cm}^{3}$. Nonionic polyacrylamide (PAM) with molecular weight of 2 14 million was used as the polymer, supplied by Shanghai Aladdin Bio-Chem. Technology Co., Ltd. Multi-walled carbon nanotubes (MWCNTs) water dispersion with mass fraction of $10 \%$ were used, manufactured by Nanjing XFNANO Materials Tech Co., Ltd. The physical properties and morphology of MWCNTs are shown in Table 2 and Figure 1(a). PVA fiber type REC15 was offered by Japan Kuraray Co. Its properties and microscopic morphology are shown in Table 3 and Figure 1(b), respectively. 


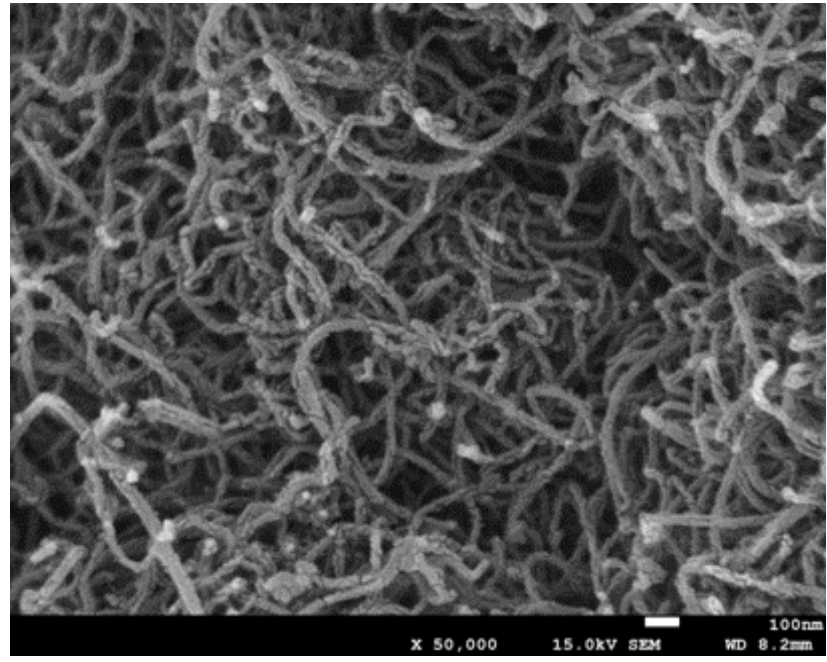

(a) CNT

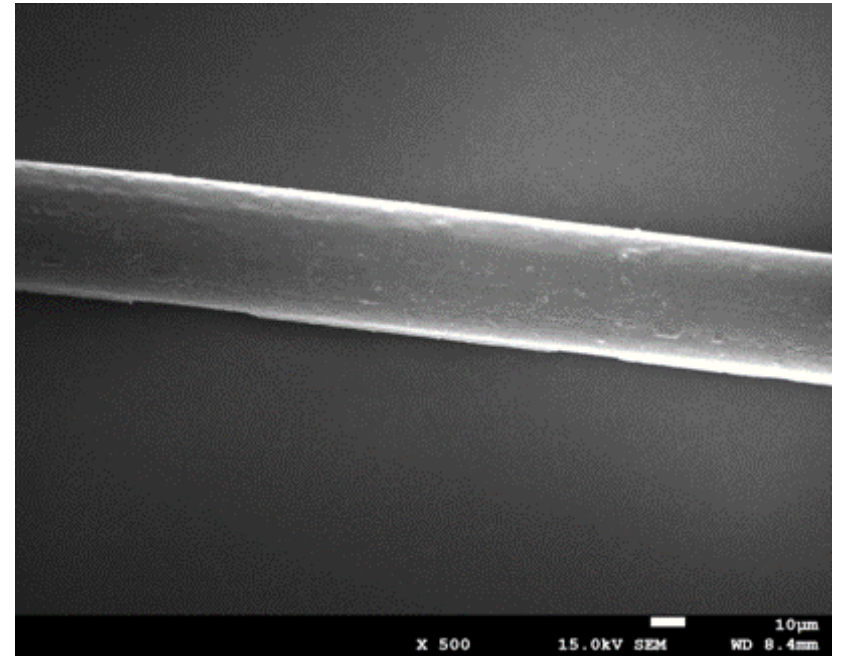

(b) PVA fiber

Figure 1: Micro-morphology of CNT and PVA fiber.

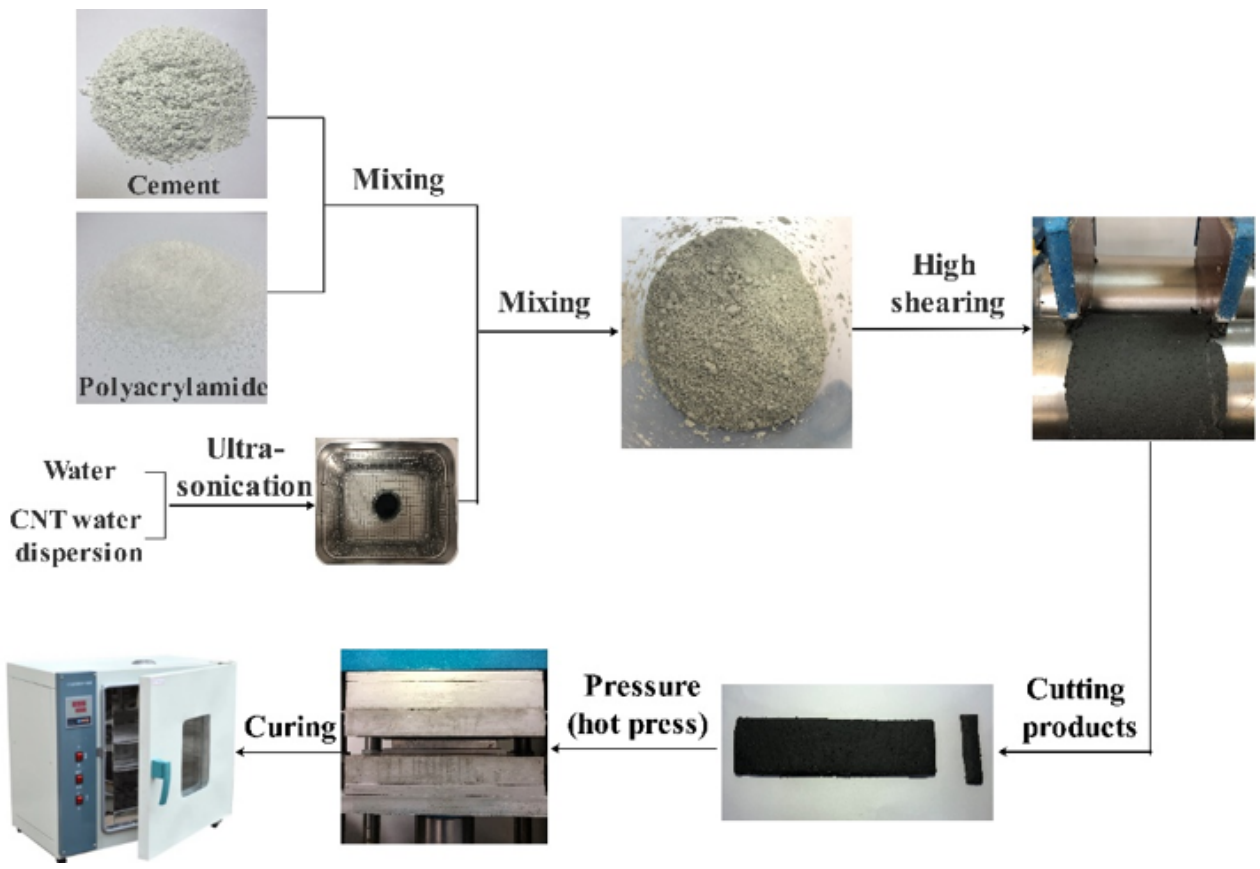

Figure 2: Basic steps to produce MDF cements with CNTs.

\subsection{Mix proportion design}

In this experiment, series $\mathrm{C}$ and $\mathrm{P}$ were designed. Series $\mathrm{C}$ is the sample with CNTs. 0.05, 0.1 and 0.15 wt.\% CNTs were added to $\mathrm{C} 1, \mathrm{C} 2$ and $\mathrm{C} 3$, respectively. Series $\mathrm{P}$ is the sample with PVA fibers. 0.5 and 1.0 vol.\% PVA fibers were added to P1 and P2, respectively. A control group was set up, in which there were no CNTs and PVA fibers. The watercement ratio of all samples was 0.15. The composition of all mixtures is shown in Table 4. Four samples were pre- pared for each group to avoid accidental errors in the experiment.

\subsection{Preparation procedure}

The key stages involved in the MDF cements manufacturing process are shown in Figure 2. The specific steps are described as follows. (1) Firstly, water and CNT water dispersion were mixed evenly, and the mixed liquid was then 


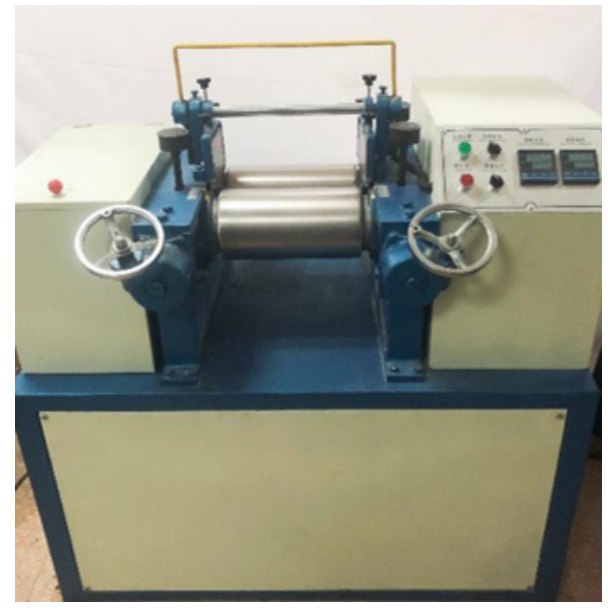

Figure 3: The twin roller mill.

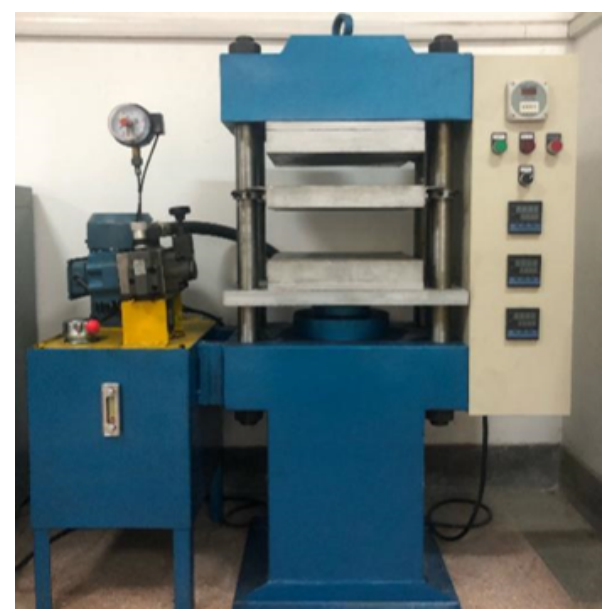

Figure 4: The flat vulcanizer.

treated by ultrasonic for $10 \mathrm{~min}$. The temperature was set to $30^{\circ} \mathrm{C}$. (2) The cement and the polymer were mixed uniformly, and stirred at high speed for $1 \mathrm{~min}$. (3) The mixture of water and CNT were poured into the mixture of cement and polymer, stirred at high speed for $2 \mathrm{~min}$. (4) The mixture was added to a twin roller mill (ZB-902, as shown in Figure 3). After a high-speed shearing for 5-8 min, sheet material in a plastic state with a thickness of about $7 \mathrm{~mm}$ was obtained. (5) The MDF cement sheet was cut according to the size of the mold. (6) The sheet was placed in the mold and the mold was put on a flat vulcanizer (ZB-910, as shown in Figure 4) in hot press for $20 \mathrm{~min}$. The temperatures of the upper and lower platen of the vulcanizer were $80^{\circ} \mathrm{C}$ and the pressure was $20 \mathrm{MPa}$. (7) The mold was taken out after hot pressing and placed at room temperature for $15 \mathrm{~min}$. (8) The specimens were cured in the oven at $80^{\circ} \mathrm{C}$ for 24 hours.

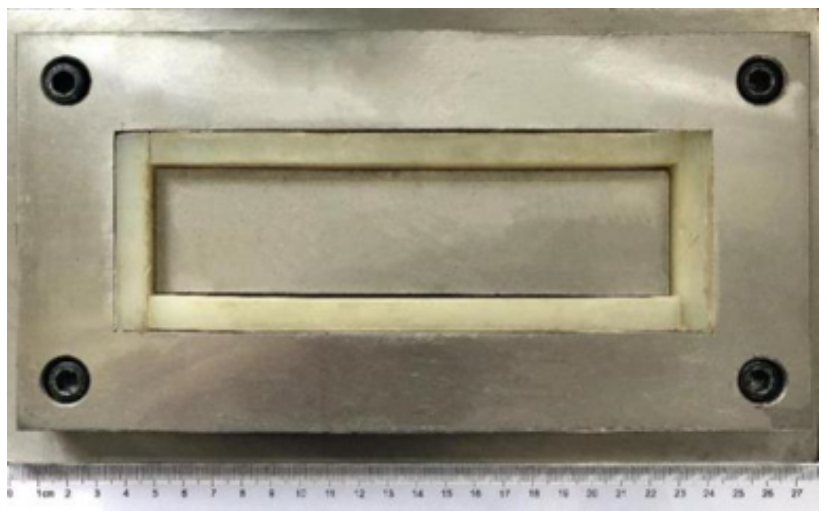

(a) The mold of specimens for mechanical test

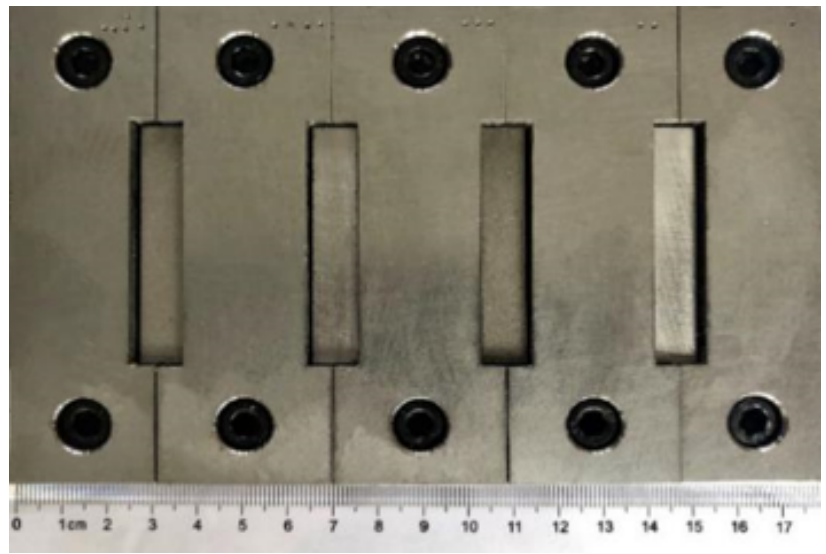

(b) The mold of specimens for damping test

Figure 5: The molds for the preparation of MDF cements.

The preparation of MDF cements with PVA fibers is simpler than that with CNTs, and the ultrasonic dispersion step is omitted. The other steps are the same as that with CNTs. Specimens had a size of $6 \times 40 \times 160 \mathrm{~mm}$ for the compressive and flexural strength test and $2.5 \times 10 \times 50 \mathrm{~mm}$ for the DMA test. The molds were shown in Figure 5.

\subsection{Material characterization tests}

\subsubsection{Microstructure}

To view the surface morphologies of the CNT/PVA fiberreinforced MDF cementitious composites, Thermal Field Emission Scanning Electron Microscope (TFE-SEM) (JSM7600F) manufactured by Japan Electronics Co., Ltd. was performed. The resolution of TFE-SEM was $3.5 \mathrm{~nm}$ and the accelerating voltage is $15 \mathrm{KV}$.

After 28 days of standard curing, the specimens were broken into small pieces with a diameter of about $5 \mathrm{~mm}$ and a thickness of no more than $3 \mathrm{~mm}$. Then, the specimens 
were soaked in absolute alcohol for one day to terminate the hydration. Finally, those specimens were dried to constant weight at $60^{\circ} \mathrm{C}$. In order to improve the electrical conductivity, the surface of the samples was coated by gold before the electron microscopic test. The temperature of TFE-SEM test is $20^{\circ} \mathrm{C}$.

\subsubsection{Mechanical properties}

Because there is no uniform standard for the mechanical properties of MDF cements, the tests of this experiment were carried out by electronic compressive and flexural testing machine according to the Chinese standard for mechanical properties of concrete (GB/T 50081-2002) [18]. The loads were measured and recorded by software connected to the machine and then converted to compressive and flexural strength according to Eqs. (1) and (2). Four replicates of each test were conducted and average values are reported.

$$
\begin{gathered}
P_{c}=F / b^{2} \\
P_{f}=3 F L / 2 b h^{2}
\end{gathered}
$$

where $F$ is the maximum force in a bent beam at the instant of failure, $L$ is the span between two supports $(100 \mathrm{~mm}), b$ is the width $(40 \mathrm{~mm})$, and $h$ is the height $(7 \mathrm{~mm})$.

\subsubsection{Damping property}

The damping performance test was conducted by the dynamic mechanical analysis (DMA) 242E Artemis (as shown in Figure 6), manufactured by NETZSCH in Germany. The test principle of the DMA is shown in Figure 7.

DMA test is a technique to obtain the dynamic modulus or loss factor of the sample varying with the temperature and frequency. These data were obtained by applying a sinusoidal alternating stress to the specimen at programmed temperature and measuring the change of its strain at the same time. The storage modulus $\left(E^{\prime}\right)$, the loss modulus $\left(E^{\prime \prime}\right)$ and the loss factor (Tan $\delta$ ) of the material can be obtained simultaneously by DMA test, and calculated according to the Eqs. (3) - (7):

$$
\begin{gathered}
\epsilon=\epsilon_{0} \sin \omega t \\
\sigma=\sigma_{0} \sin (w t+\delta) \\
E^{\prime}=\sigma_{0} \cos \delta / \epsilon_{0}
\end{gathered}
$$

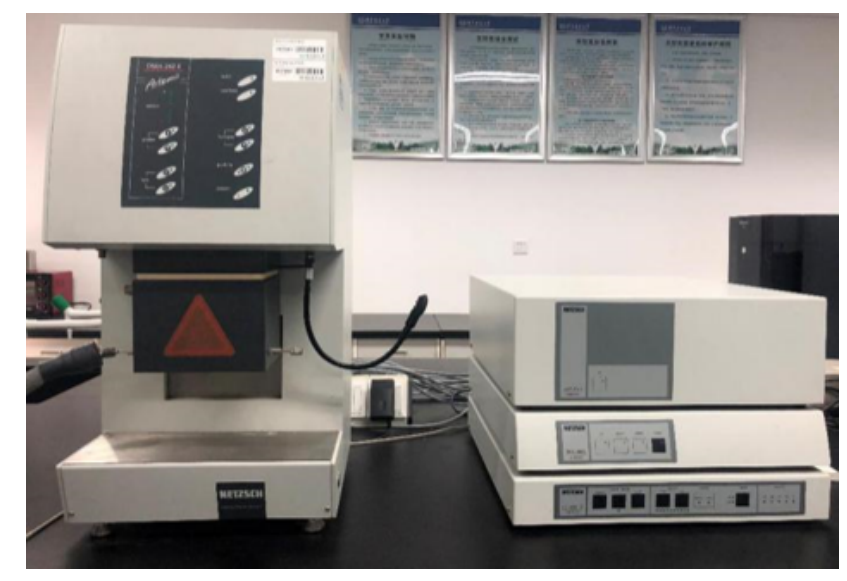

Figure 6: DMA 242 E Artemis.

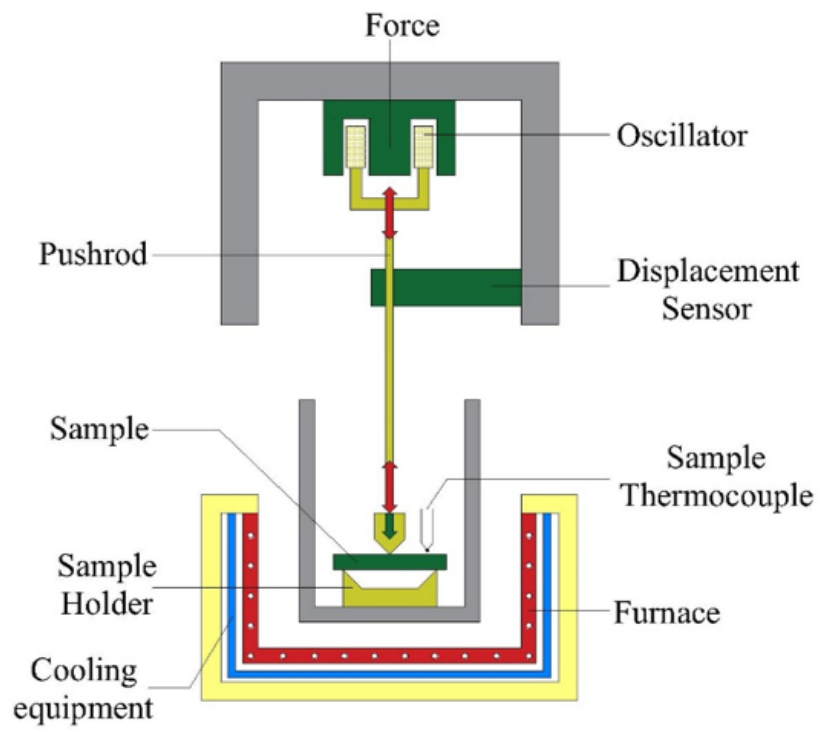

Figure 7: The functional principle of DMA 242 E Artemis.

$$
\begin{gathered}
E^{\prime \prime}=\sigma_{0} \sin \delta / \epsilon_{0} \\
\tan \delta=E^{\prime} / E^{\prime \prime}
\end{gathered}
$$

Where $\omega$ is the angular frequency; $\delta$ is the phase angle; $t$ is time; $\epsilon_{0}$ is the strain peak; $\sigma_{0}$ is the stress peak; $E^{\prime}$ is the storage modulus, which refers to the energy stored by the material due to elastic deformation during the deformation process, reflecting the elastic component of the viscoelasticity of the material, and characterizing the stiffness of the material; $E^{\prime \prime}$ is the loss modulus, which refers to the energy dissipated in the form of heat due to the viscous deformation of the material during the deformation process, reflecting the viscous component of the material and characterizing the damping property of the material; $\tan \delta$ is the loss factor $\left(E^{\prime \prime} / E^{\prime}\right)$, which is the ratio of the en- 


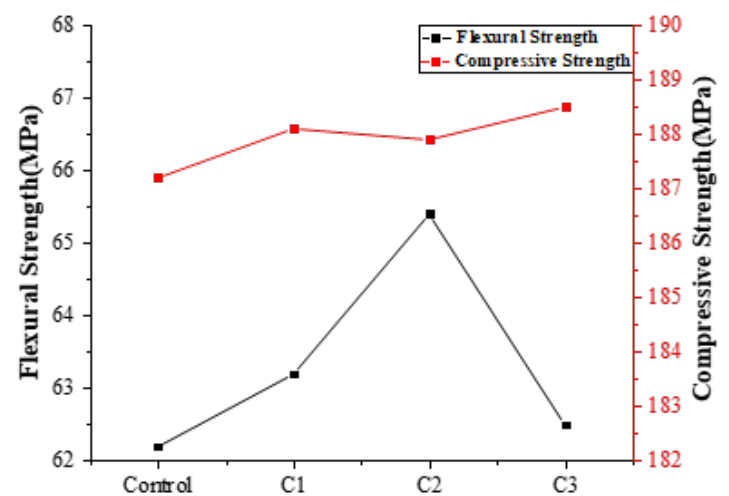

(a) MDF cements with CNTs

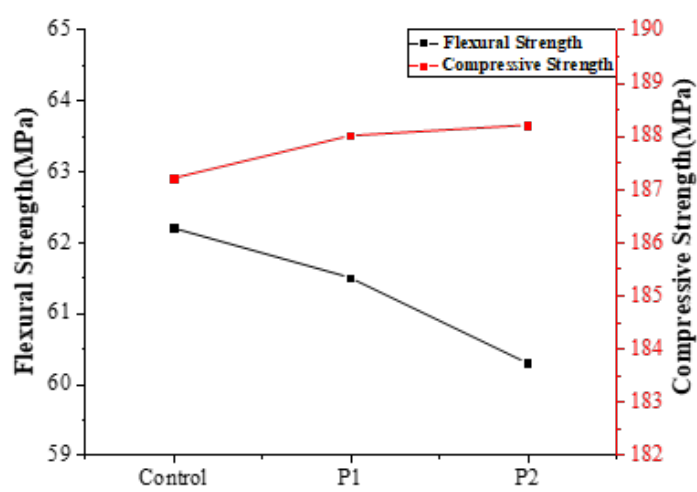

(b) MDF cements with PVA fibers

Figure 8: Flexural strength and compressive strength of specimens at 28 days.

ergy dissipated by the material during deformation to the maximum storage modulus [19].

The deformation modes of DMA include three-point bending mode, single/double cantilever beam mode, tension mode, compression/penetration mode and shear mode. Because the stiffness of cement-based materials is very large, the three-point bending mode was chosen. In this experiment, the span of the two supports in the threepoint bending mode was $50 \mathrm{~mm}$. The sample was subjected to periodic deformation with an amplitude of $7 \mu \mathrm{m}$, and the frequencies were $0.5 \mathrm{~Hz}, 1.0 \mathrm{~Hz}, 1.5 \mathrm{~Hz}, 2.0 \mathrm{~Hz}, 2.5$ $\mathrm{Hz}$. Since most cement-based materials work at room temperature, all tests were carried out at $25^{\circ} \mathrm{C}$.

\section{Results and discussion}

\subsection{Mechanical properties}

\subsubsection{Compressive strength}

The results of the compressive strength of CNT/PVA fiberreinforced MDF cementitious composites are shown in Figure 8. It can be found that the addition of CNTs and PVA fibers had little contribution to the compressive strength. The compressive strengths of the $\mathrm{C} 1, \mathrm{C} 2$, and $\mathrm{C} 3$ groups was increased by $0.48 \%, 0.27 \%$, and $0.69 \%$, respectively. The compressive strength of the P1 and P2 groups was increased by $0.43 \%$ and $0.53 \%$, respectively. Because of the transverse expansion and cracking during compression, most of the CNTs and PVA fibers were in the compressive state and could not play a bridging role in the crack.

\subsubsection{Flexural strength}

The results of the flexural strength of CNT/PVA fiberreinforced MDF cementitious composites are shown in Figure 8. The results show that the addition of CNTs and PVA fibers had a significant effect on the flexural strength. As shown in Figure 8(a), the flexural strength was increased first and then decreased with the increase of CNT content. The critical threshold of the CNT content in MDF cements was $0.10 \mathrm{wt} . \%$, and the flexural strength was increased by $5.14 \%$. When the CNT content was less than $0.10 \mathrm{wt} . \%$, the flexural strength was increased with the increase of CNT content.

The enhancement mechanism of the flexural strength of MDF cements by the addition of CNTs can be explained as follows: MDF has a very low water-cement ratio with polymer. After roll milling and hot pressing, it forms a very dense and uniform matrix [20]. CNTs can be evenly distributed in the matrix when a proper amount of CNTs is added. After the rolling of the open mill, CNTs are strongly connected with the matrix and polymer through mechanical interlocking, chemical bonding and van der Waals interactions [21]. Therefore, CNTs can form a strong threedimensional space connection when they are uniformly dispersed in MDF, which can improve the flexural strength. The strengthening mechanism of flexural strength of MDF cements by CNTs can be summarized as three mechanisms, includes of fiber bridging, crack deflection and fiber slippage [22]. (1) Fiber bridging: When the cement-based material is subjected to external force, it will deform. And the concrete will crack in tension when the external force exceeds its stress limit. When the crack propagates to the area where the CNTs are located, the CNTs can restrain the crack propagation by bridging, as shown in Figure 10(a). 
Hunashyal et al. believe that the CNTs can bridge the cracks, so that crack development can be effectively controlled, and these cracks will not continue to develop until the CNTs are destroyed or pulled out by the increasing external stress [23], as shown in Figure 10(b). (2) Crack deflection: Compared with the matrix, the mechanical properties of the interface transition zone (ITZ) between the CNTs and the matrix are very poor. The ITZ is a weak link in the composite materials. When the crack reaches the region where the CNTs are located at a small angle (less than $90^{\circ}$ ), the crack will develop along the direction of the weak ITZ. Therefore, the change of the path will increase the development path of the crack in the matrix and delay the failure process. (3) Fiber slippage: With the increase of the crack width, the CNTs at the crack will slip because of the high strength of the CNTs. When the shear force completely exceeds the bonding force between the CNTs and the cement matrix, the CNTs will be pulled out. This process consumes a great deal of external energy and slows down the crack propagation.

However, when the CNT content was between $0.10 \%$ and $0.15 \%$, the flexural strength decreased with the increase of the CNT content. CNTs have small scale and large specific surface area, so there is a strong van der Waals force between the CNTs and it is prone for CNTs to adsorption and agglomeration [24]. When the content is too high, the CNTs wound into agglomerates cannot play a reinforcing role in the extremely dense MDF, but form weak defects. Therefore, the addition of defects in the extremely dense matrix made a negative contribution to the flexural strength.

Luo [25] found that the flexural strength of the concrete was the highest when the CNT content is $2 \mathrm{wt} . \%$ in the ordinary cement systems. In this experiment, the optimum content of CNT is $0.10 \mathrm{wt} . \%$. When the content was more than 0.10 wt.\%, the flexural strength began to decrease. The ordinary cement matrix contains $25-30$ vol. $\%$ of pores with diameter ranging from nanometer to micrometer. In the ordinary cement matrix, when the CNT content exceeds the effective value, the excess CNTs will agglomerate in the pores and make the matrix denser. Therefore, the mechanical properties can be improved after the content is higher than the effective value in the ordinary cementbased material. However, MDF cement-based materials are extremely dense (as shown in Figure 9), in which the diameter of the largest pore is less than $10 \mu \mathrm{m}$. When the CNT content reach the effective value, the excess CNTs agglomerate to form defects in the MDF. The flexural strength of the material is sensitive to its internal defects, so too much CNTs will reduce its flexural strength.
As shown in Figure 8(a), the addition of PVA fibers had a negative contribution to the flexural strength, which was completely opposite to the regularity of that with CNTs. The flexural strength of the MDF cements was decreased with the increase of the PVA fiber content. The flexural strength of the MDF cements was 62.2 MPa without fibers. While the flexural strength was $61.5 \mathrm{MPa}$ with $0.5 \mathrm{vol} . \%$ PVA fibers and $60.3 \mathrm{MPa}$ with 1.0 vol.\% PVA fibers, which was decreased by $1.13 \%$ and $3.05 \%$, respectively. There are three reasons: (1) The diameter of the PVA fiber is $40 \mu \mathrm{m}$ and the length is $12 \mathrm{~mm}$. The scale of the PVA fiber is much larger than the pores in the MDF cements. Therefore, the addition of PVA fibers formed internal defects. (2) The PVA fiber is a kind of soft fiber with a length-diameter ratio of 300 , which is difficult to disperse when stirring. (3) Kuraray REC15 PVA fibers used in the experiment were coated with oil to reduce the bonding between the fibers and cement matrix. The smooth surface made it easy to slip, so the addition of PVA fibers cannot prevent the development of cracks, as shown in Figure 11. Therefore, the addition of

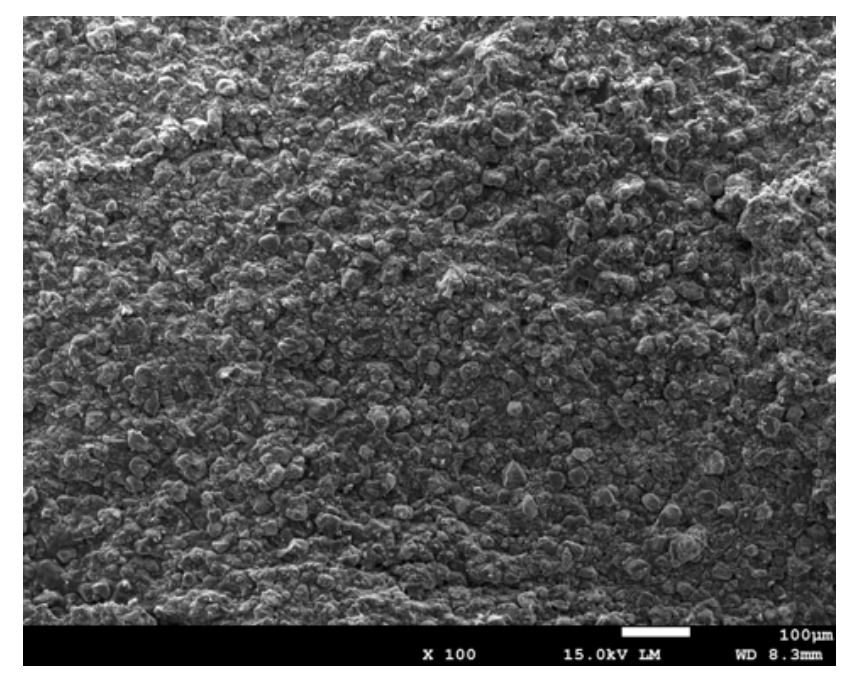

Figure 9: The microstructure of the MDF cements.

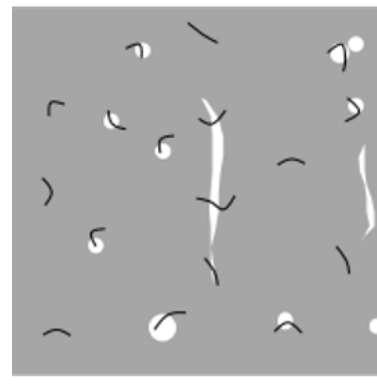

(a) Microcrack

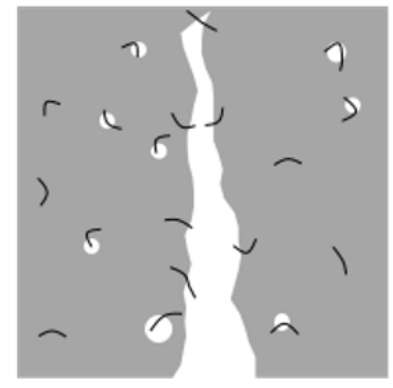

(b) crack growth
Figure 10: Crack bridging of CNTs. 


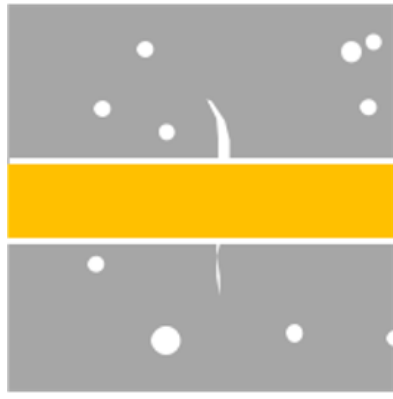

(a) Microcrack

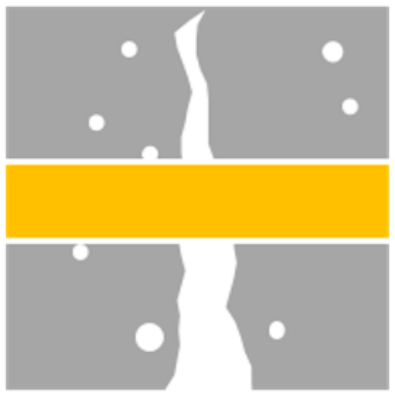

(b) crack growth

Figure 11: Crack bridging of PVA fibers.

PVA fibers to such a dense MDF cement-based material reduced its flexural strength.

However, it was found that the flexural strength of the ordinary cement-based materials was greatly improved with the addition of the PVA fibers in the previous studies. Peyvandi [26] found that adding 1.0 vol.\% PVA to concrete increased the flexural strength by $50 \%$. The ordinary cement-based materials have a lot of defects and the flexural strength is very low, so the addition of fibers plays the role of bridging cracks without additional defects. Therefore, PVA fibers can improve the flexural strength of the ordinary cement-based materials.

\subsection{Damping performance}

The loss factor of CNT/PVA fiber-reinforced MDF cementitious composites is shown in Figure 12. All the loss factors decreased with the increase of frequency. When the frequency was low, the vibration speed and the deformation were also slow, so the fibers had the process of slippage. When the frequency was high, the vibration speed was fast and the deformation time was short. The slippage distance of the fibers was reduced and the energy dissipation capacity was reduced. The samples of Control, C1, C2, C3, P1, P2 all showed this regularity.

The addition of CNTs and PVA fibers had a positive contribution to the damping performance of the material. The damping property of MDF cements with PVA fibers was much higher than that with CNTs. The damping property of $\mathrm{C} 2$ was the best among the CNT-reinforced cementitious composites, and the loss factor of $\mathrm{C} 2$ was increased by $43.7 \%$ at $0.5 \mathrm{~Hz}$. The loss factor of $\mathrm{P} 2$ was increased by $76.9 \%$, which is nearly twice greater than the improvement caused by $0.1 \mathrm{wt} . \%$ CNTs.

Generally, the damping property of cement-based materials decreases with the increase of mechanical prop-

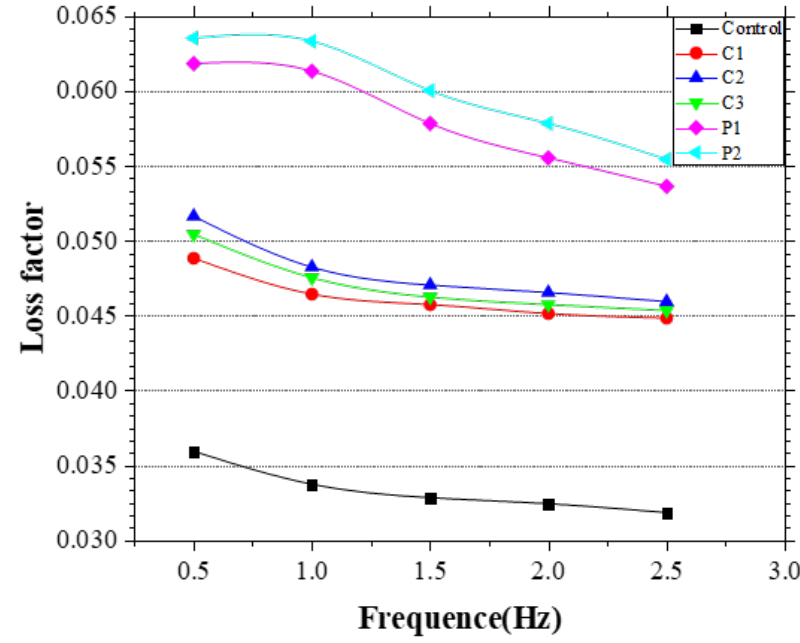

Figure 12: Loss factors of MDF cements obtained by DMA test.

erties. However, the MDF cement based composites have high compressive and flexural strength with brittle failure, and the damping property is better than that of ordinary cement based composites. In the experiment of Liew et al. [27], the flexural strength of the reference group was about 7MPa, and the highest loss factor was only 0.029 . However, the flexural strength of the reference group in this experiment was $62.2 \mathrm{MPa}$, and the highest loss factor was 0.036 because the polymer was added to MDF cement-based composites. As a kind of viscoelastic material, polymer can convert the absorbed mechanical energy into heat energy and volatilize it, which improves the damping property. And viscoelastic materials have good toughness. Adding polymer into cement-based materials can not only fill the void but also restrict the generation and development of micro-cracks in concrete. Polymer can significantly improve the pore structure characteristics of concrete, and increase the friction of particles in the concrete, which plays a role in energy dissipation and improves the damping performance.

The addition of CNT can improve the damping property of MDF cement-based materials, mainly for the three reasons. (1) The strength of CNT is very high, which is much higher than that of cement matrix. When there were cracks in the region where the CNTs were located, the CNTs would not break, so there must be slippage. (2) The specific surface area of CNT is $40-300 \mathrm{~m}^{2} / \mathrm{g}$, so it has a large contact area with the matrix. As more interfaces were formed, more slippage displacements were generated and more energy was consumed. (3) A single MWCNT contains several concentric tubes. The interface slippage and friction between tubes results in energy dissipation [28]. In addition, 


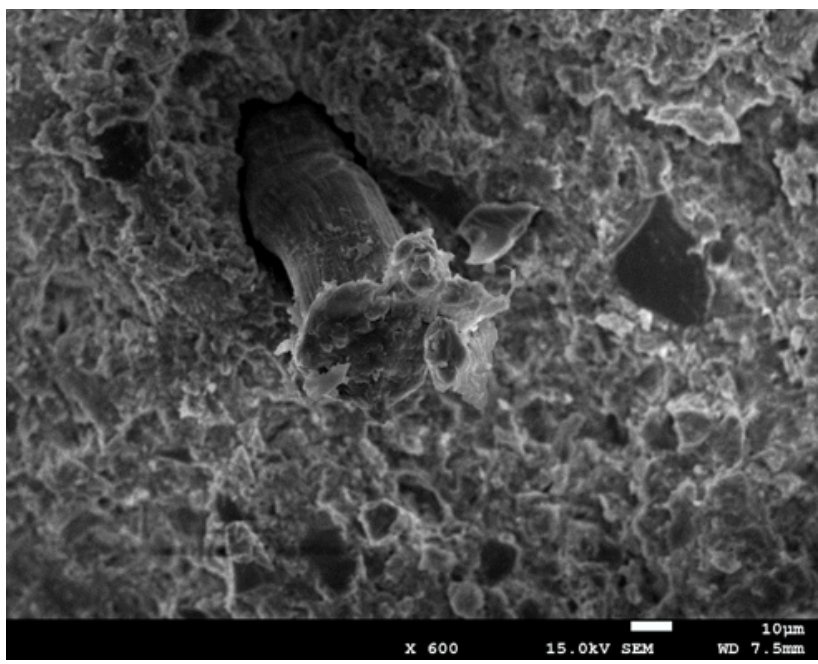

Figure 13: The interfacial transition zone between the PVA fibers and matrix.

the nano-pores in MWCNTs could also produce resonance and reduced the impact in the process of vibration.

The damping property of MDF cements with PVA fibers is much higher than that with CNTs. The surface of the PVA fibers was oiled and very smooth, which weaken the bond strength between the fibers and matrix. The ITZ between the fibers and matrix was large (as shown in Figure 13), which was favorable for fiber slippage. In the process of crack growth, PVA fibers slipped to achieve energy dissipation, as shown in Figure 14(b). However, the bond between the CNTs and matrix was jagged and almost integrated [21]. When the crack grew, it was very difficult for the CNTs to slip because the bond between the CNTs and matrix was too strong, and only a limited slippage distance could be generated, as shown in Figure 14(a). Therefore, the improvement of the damping property of MDF cementbased materials with CNTs was mainly due to the slippage between the inner tubes of the CNTs rather than the slippage between the CNTs and matrix [29]. The main reason for the improvement of damping property of composite materials is the slippage friction between different materials. Therefore, the contribution of the CNTs to the damping property of MDF cement-based materials was far lower than that of the PVA fibers.

However, the previous studies have shown that the PVA fibers have no significant effect on the damping property of the concrete. Noushini et al. [30] added 0.25 vol.\% and 0.5 vol.\% PVA fibers to the concrete and measured the damping ratio through impact resonance test. It was found that addition of PVA fibers in low volume fraction had no significant effect on concrete material damping ratio. There are two reasons for this. (1) PVA fiber is hy-

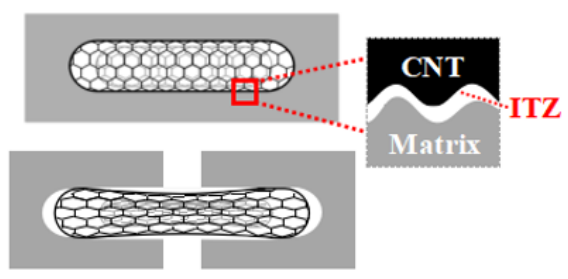

(a) MDF cements with CNTs

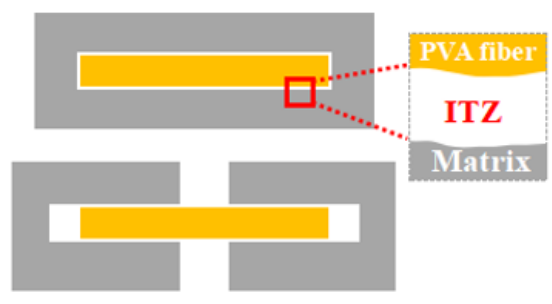

(b) MDF cements with PVA fibers

Figure 14: Energy dissipation mode of MDF cements with (a) CNTs and (b) PVA fibers.

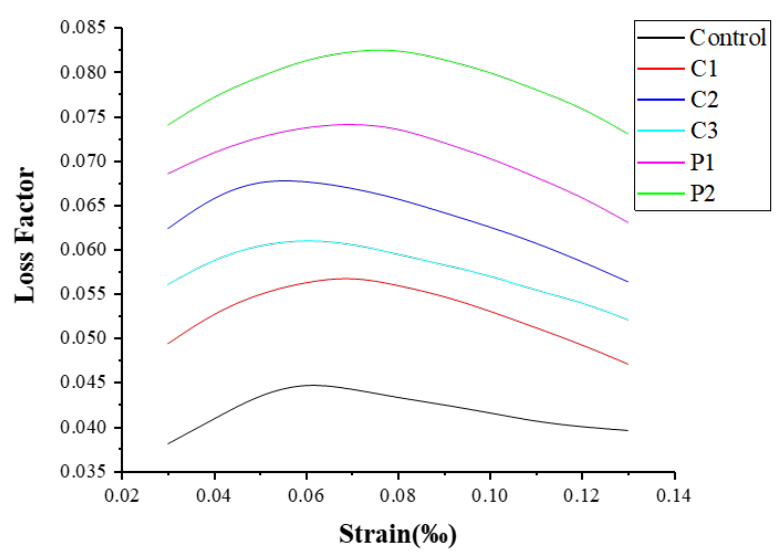

Figure 15: $\operatorname{Tan} \delta$ of MDF cements as a function of the dynamic strain at $1 \mathrm{~Hz}$.

drophilic. Due to the presence of hydroxyl groups in its main chain, PVA fibers formed a strong bond with cement matrix [31]. The bond between the fibers and matrix was so strong that it was difficult to slip. Therefore, if the fibers were not coated with oil, it could not play the role of energy consumption without slippage. (2) The internal structure of MDF cements was very compact. When the external stress caused small deformation, the fibers were easy to slip.

The relationship between the strain and loss factor of MDF cements at $1 \mathrm{~Hz}$ was shown in Figure 15. By observing the strain corresponding to the loss factor peak of each sample, it was found that the strain corresponding to the 


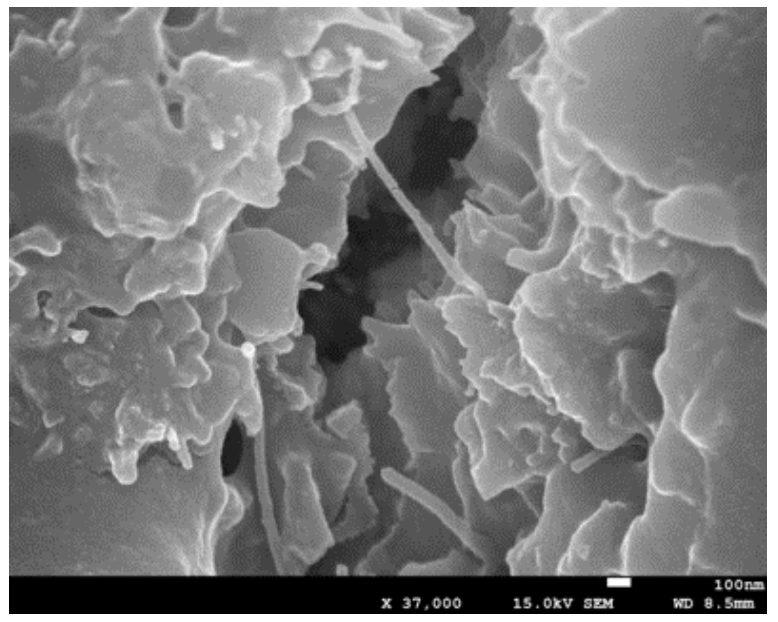

(a) $\mathrm{C} 2$

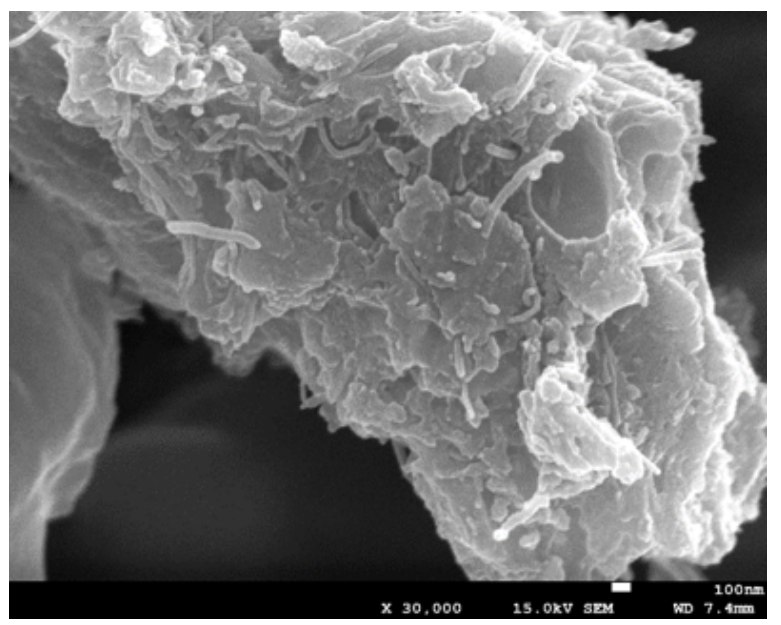

(c) $\mathrm{C3}$

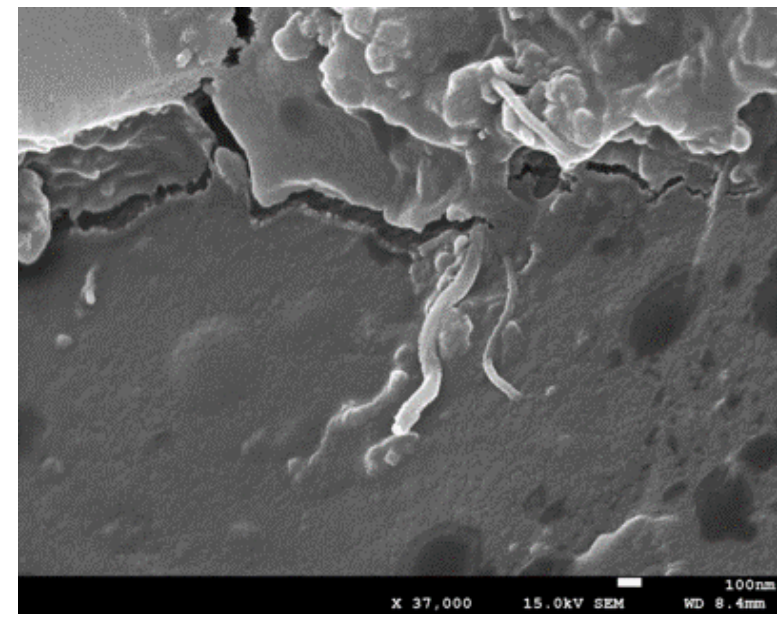

(b) $\mathrm{C} 2$

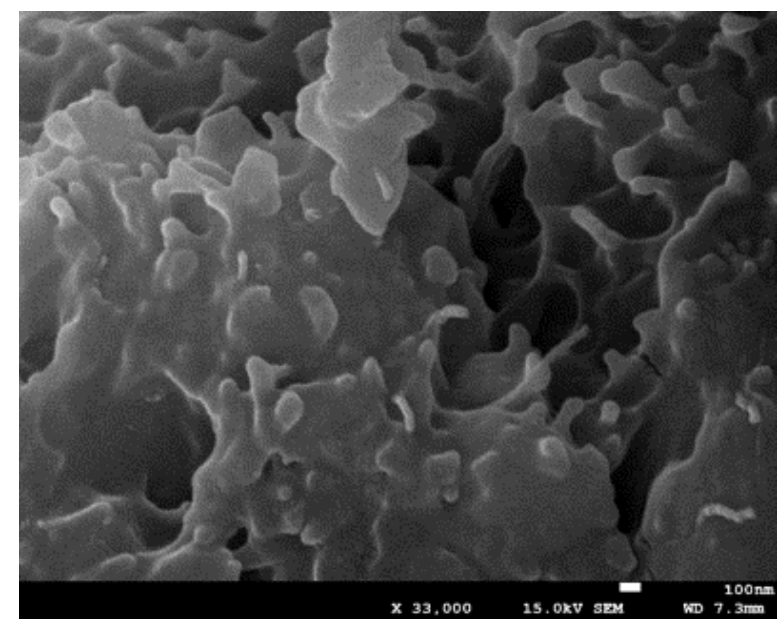

(d) C3

Figure 16: SEM image of CNT-reinforced MDF.

loss factor peak of the CNTs was about $0.05 \%$. The strain corresponding to the loss factor peak of the PVA fibers was about $0.08 \%$. The strain corresponding to the loss factor peak reflected the slippage distance between the fibers and matrix. So the slippage of PVA fibers in the matrix was longer than that of CNTs.

\subsection{Microscopy}

The morphologies of hydrated CNT-reinforced MDF cementitious composites with a CNT content of $0.10 \mathrm{wt} . \%$ and 0.15 wt.\% after 28 days of curing are shown in Figure 16. From the morphologies of $\mathrm{C} 2$, it can be seen that the CNTs were well mixed in the cement matrix and the microstructure is uniform and dense. When CNTs are uniformly dispersed in the paste, they provide nucleation sites for the growth of hydration products owing to their high surface energy. CNTs played a role of crack bridging in the matrix, as shown in the Figure 16(a) and (b). The CNTs sewed up the cracks like threads, which effectively prevented the cracks from developing until the CNTs were broken or pulled out. In the process of CNTs being pulled out or destroyed, the energy brought by the external destructive stress was effectively consumed. As shown in Figure 16(c) and (d), the CNTs were embedded in the cement matrix, and the bonding was so strong that the CNTs and matrix were almost integrated. When the crack propagated, the bonding force between the CNTs and the matrix was too strong to slip. This also verified the reason why the damping property of MDF cement-based material with CNTs was lower than that of PVA fibers.

The morphologies of hydrated PVA fiber-reinforced MDF cementitious composites with 1.5 vol.\% PVA fibers 


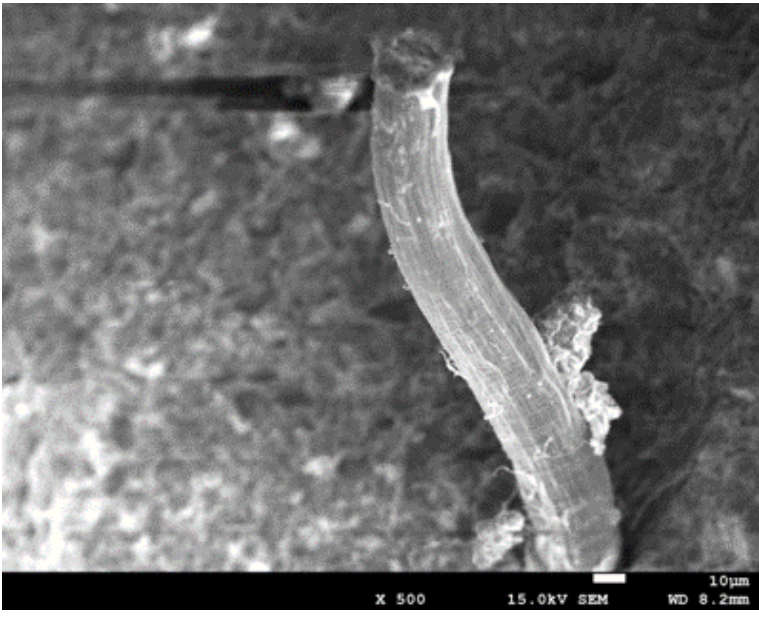

(a) complete pull-out and intact

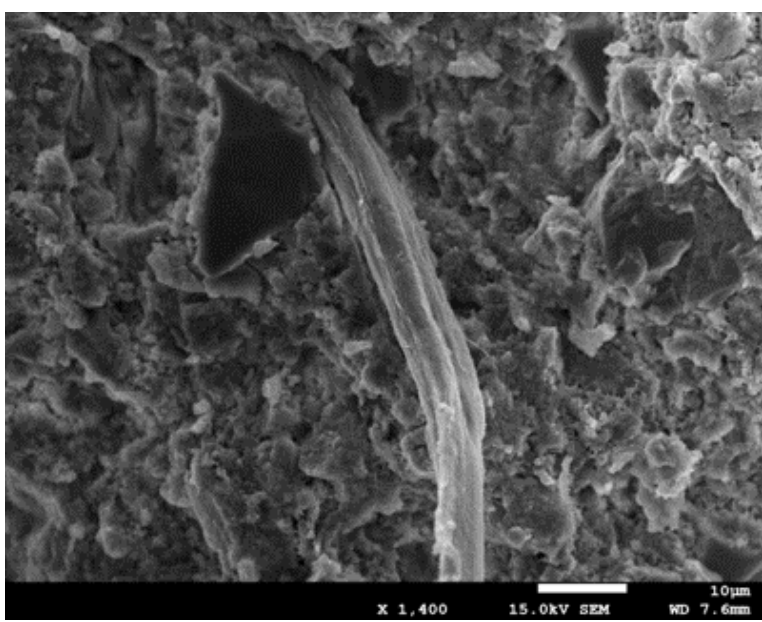

(c) fiber rupture

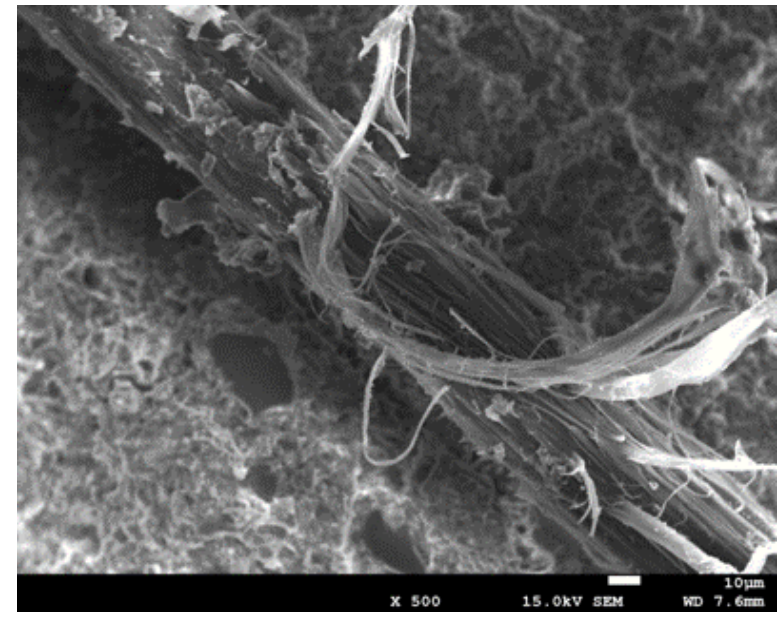

(b) pull-out with sever surface abrasion

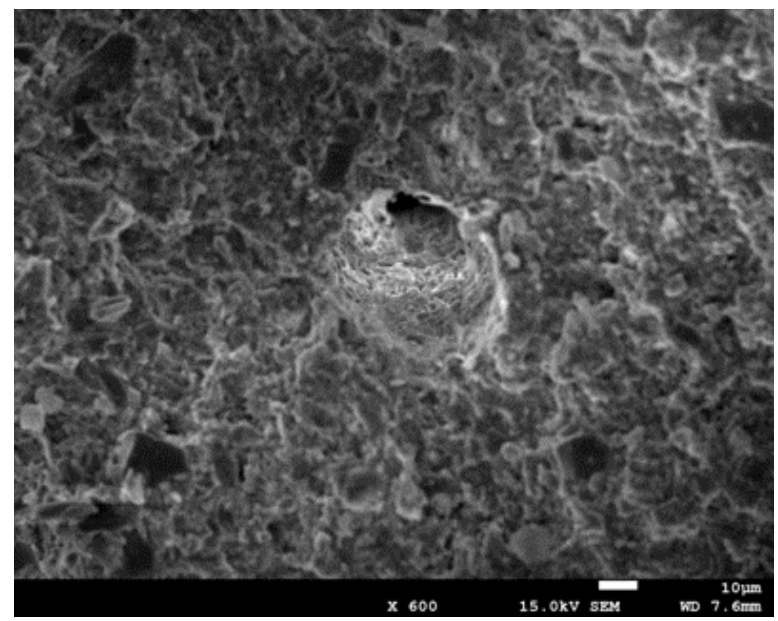

(d) hole after fiber pullout

Figure 17: SEM image of different failure phenomenon of PVA fibers in MDF.

after 28 days of curing are shown in Figure 17. The PVA fiber in Figure 17(a) was completely pulled out with slight abrasion on the surface, and this type of fiber was weakly bonded to the matrix. The surface of the fiber in Figure 17(b) was severely worn after pullout, and this type of fiber was strongly bonded to the matrix. The diameter of the fiber in Figure 17(c) was reduced, and it could be inferred that they have been broken. This type of fiber was strongly bonded to the matrix. Figure 17(d) shows the holes left after the fiber was pulled out. When the bonding strength between the fibers and matrix was weak, the fibers were easy to slip. The process of sliding could dissipate energy and improve the damping performance. When the bonding strength between the fibers and matrix was strong, the fibers would break directly without slippage, which had no contribution to damping property.

\section{Conclusion}

In this paper, the effect of multi-scale fibers on mechanical and damping Properties of MDF cements were studied, and the following conclusions were drawn:

1. The addition of CNTs and PVA fibers had little contribution to the compressive strength of MDF cements. Because of the transverse expansion and cracking during compression, most of the CNTs and PVA fibers were in the compressive state and could not play a bridging role in the crack.

2. The flexural strength of MDF cements was increased first and then decreased with the increase of CNT content. The critical threshold of the CNT content in the MDF cements was $0.10 \mathrm{wt} . \%$, and the flexural strength was increased by $5.14 \%$. The CNTs en- 
hanced the flexural strength by fiber bridging, crack deflection and fiber slippage. When the content was too high, the CNTs wound into agglomerates formed weak defects, which led to the decrease of flexural strength.

3. The flexural strength of MDF cements was decreased with the increase of the PVA fiber content. The size of PVA fiber is larger than that of the pores in the MDF cement, so the fibers were easy to agglomerate and form internal defects. Moreover, the oiled fibers had poor adhesion to the matrix, which could not prevent the development of cracks.

4. The 0.10 wt. $\%$ CNTs and 1.0 vol.\% PVA fibers improved the loss factor by $43.7 \%$ and $76.9 \%$, respectively. The addition of CNTs and PVA fibers had a positive contribution to the damping performance of the material. The damping property of MDF cements with PVA fibers was much higher than that with CNTs. The main reason for the improvement of damping property of composite materials was the slippage friction between different materials. The bonding between the PVA fibers and matrix was weak, so it was easy for the fibers to slip to dissipate energy. However, the bonding between the CNTs and matrix is too strong to slip, so the CNTs had smaller contribution to the MDF cements.

Acknowledgement: This research was financially supported by the National Natural Science Foundation of China (51978339, 51678309), Natural Science Foundation of Jiangsu Province of China (BK20161529), State Key Laboratory of Silicate Materials for Architectures (Wuhan University of Technology), Priority Academic Program Development Jiangsu Higher Education Institutions (PAPD). Thank Mr. Min of Advanced analysis and testing center of Nanjing Forestry University for the help of the TFE-SEM tests.

\section{References}

[1] Birchall JD, Howard AJ, Kendall K. Flexural strength and porosity of cements. Nature. 1981 Jan;289(1):388-90.

[2] Mojumdar S, Mazanec K, Drabik M. Macro-defect-free (MDF) cements. J Therm Anal Calorim. 2006 Mar;83(1):135-39.

[3] Donatello S, Tyrer M, Cheeseman CR. Recent developments in macro-defect-free (MDF) cements. Constr Build Mater. 2009 May;23(5):1761-67.

[4] Tomar P, Lakhani R, Chhibber VK, Kumar R. Macro-defect free cements: a future oriented polymer composite materials for construction industries. Compos Interface. 2018 Jan;25(5):607-27.

[5] Bonapasta AA, Buda F, Colombet P. Cross-Linking of Poly (vinyl alcohol) Chains by Al lons in Macro-Defect-Free Cements: A The- oretical Study. Chem Mater. 2000 Feb;12(3):738-43.

[6] Bonapasta AA, Buda F, Colombet P. Interaction between Ca lons and Poly (acrylic acid) Chains in Macro-Defect-Free Cements: A Theoretical Study. Chem Mater. 2001(Dec);13(1):64-70.

[7] Bonapasta AA, Buda F, Colombet P, Guerrini G. Cross-Linking of Poly (Vinyl Alcohol) Chains by Ca lons in Macro-Defect-Free Cements. Chem Mater. 2002 Feb;14(3):1016-22.

[8] Santos RS, Rodrigues FA, Segre N, Joekes I. Macro-defect free cements Influence of poly (vinyl alcohol). cement type. and silica fume. Cem Concr Res. 1999 May;29(5):747-51.

[9] Li Y, Ding Q. Research on the properties of fiber reinforced MDF cement. Journal of Hebei Institute of Technology. 2001;23(1):4852 (in Chinese).

[10] Sanchez F, Sobolev K. Nanotechnology in concrete - A review. Constr Build Mater. 2010 Nov;24(11):2060-71.

[11] Sharma S, Kothiyal NC. Facile growth of carbon nanotubes coated with carbon nanoparticles: A potential low-cost hybrid nanoadditive for improved mechanical. electrical. microstructural and crystalline properties of cement mortar matrix. Constr Build Mater. 2016 Oct;123(1):829-46.

[12] Douba A, Emiroglu M, Kandil UF. Very ductile polymer concrete using carbon nanotubes. Constr Build Mater. 2019 Jan;196(1):46877.

[13] Fakhim B, Hassani A, Rashidi A, Ghodousi P. Preparation and microstructural properties study on cement composites reinforced with multi-walled carbon nanotubes. J Compos Mater. 2013 Dec;49(1):85-98.

[14] Li W, Ji W, Y. Liu, Xing F, Liu Y. Damping Property of a CementBased Material Containing Carbon Nanotube. J Nanomater. 2015 Dec;16(1):418-25.

[15] Chen Z, Lim JLG, Yang E. Ultra high performance cement-based composites incorporating low dosage of plasma synthesized carbon nanotubes. Mater Design. 2016 Oct;108(1):479-87.

[16] Koratkar N, Wei BQ, Ajayan PM. Carbon Nanotube Films for Damping Applications. Adv Mater. 2002 Jul;14(13):997-1000.

[17] Thostenson ET, Ren Z, Chou T. Advances in the science and technology of carbon nanotubes and their composites: a review. Compos Sci Technol. 2001 Oct;61(13):1899-1912.

[18] GB (2003) GB/T 50081-2002: Standard for test method of mechanical properties on ordinary concrete. Ministry of Construction of the People's Republic of China. Beijing. China. (in Chinese).

[19] Liu T, Song W, Zou D, Li L. Dynamic mechanical analysis of cement mortar prepared with recycled cathode ray tube (CRT) glass as fine aggregate. J Clean Prod. 2018 Feb;2(174):1436 43.

[20] Chu TJ, Robertson RE. Viscoelastic behaviour of macro-defectfree cement. J Mater Sci. 1994 Sep;29(10): 2683-90.

[21] Gardea F, Glaz B, Riddick J, Lagoudas DC, Naraghi M. Energy Dissipation Due to Interfacial Slip in Nanocomposites Reinforced with Aligned Carbon Nanotubes. ACS Appl Mater Inter. 2015 Apr;7(18):9725-35.

[22] Xu S, Liu J, Li Q. Mechanical properties and microstructure of multi-walled carbon nanotube-reinforced cement paste. Constr Build Mater. 2015 Feb;76(1):16-23.

[23] Hunashyal AM, Lohitha SJ, Quadri SS, Banapurmath NR. Experimental investigation of the effect of carbon nanotubes and carbon fibres on the behaviour of plain cement composite beams. The IES Journal Part A: Civil \& Structural Engineering. 2011 Feb;4(1):29-36. 
[24] Ma PC, Siddiqui NA, Marom G, Kim JK. Dispersion and functionalization of carbon nanotubes for polymer-based nanocomposites: a review. Compos Part A Appl Sci Manufa. 2010 Oct;41(10):134567.

[25] Luo J, Duan Z, Xian G, Li Q, Zhao T. Damping Performances of Carbon Nanotube Reinforced Cement Composite. Mech Adv Mater Struc. 2014 Oct;22(3):224-32.

[26] Peyvandi A, Soroushian P, Jahangirnejad S. Enhancement of the structural efficiency and performance of concrete pipes through fiber reinforcement. Constr Build Mater. 2013 Aug;45(1):36-44.

[27] Liew KM, Kai MF, Zhang LW. Mechanical and damping properties of CNT-reinforced cementitious composites. Compos Struct. 2017 Jan;160(1):81-88.
[28] Zhang Y, Peng H, Lu W. Shear stress transfer model for evaluating the fracture behavior of SHCCs for RC shear strengthening. Mag Concrete Res. 2018 May;70(10):512-18.

[29] Chi L, Lu S, Yao Y. Damping additives used in cement-matrix composites: A review. Compos Part B Eng. 2019 May;164(1):2636.

[30] Noushini A, Samali B, Vessalas K. Effect of polyvinyl alcohol (PVA) fibre on dynamic and material properties of fibre reinforced concrete. Constr Build Mater. 2013 Dec;49(1):374-83.

[31] Arain MF, Wang M, Chen J, Zhang H. Study on PVA fiber surface modification for strain-hardening cementitious composites (PVASHCC). Constr Build Mater. 2019 Feb;197(1):107-16. 